\title{
Concerns raised about Ontario's new regime for bariatric surgery
}

Published at www.cmaj.ca on Jan. 4

$\mathrm{T}$ he province of Ontario's move to reduce costs by expanding domestic capacity to perform bariatric surgery is raising concerns about longer waiting lists and regional variations in the availability of surgery.

The move could also jeopardize the lives of morbidly obese patients, charges Dr. Yoni Freedhoff, director of the Bariatric Medical Institute, a privately run weight management centre in Ottawa, Ontario.

"People do die on wait lists. This is a sick population," he says. "This isn't somebody who needs a hip or a knee. This is someone whose medical condition is serious enough that it can cause permanent damage and/or death while they're waiting."

Also at issue are significant changes in the referral process for patients requiring bariatric surgery, the most common form of which is a gastric bypass, a procedure to reduce the functional volume of the stomach. Complications can occur and it's been estimated that as many as $2 \%$ of all patients suffer a surgery-related death within a month (N Engl J Med 2007; 357:753-61).

Under Ontario's new regime, family physicians will no longer be allowed to determine whether a patient needs bariatric surgery. Rather, they must refer patients to one of five designated assessment centres, which will determine whether surgery is warranted, after patients have participated in and failed - a multidisciplinary weight management program of at least three months duration.

After an estimated 1660 residents ventured to United States surgical centres in 2008, Ontario Premier Dalton McGuinty announced in February 2009 that his government would spend $\$ 75$ million to expand the province's capac-

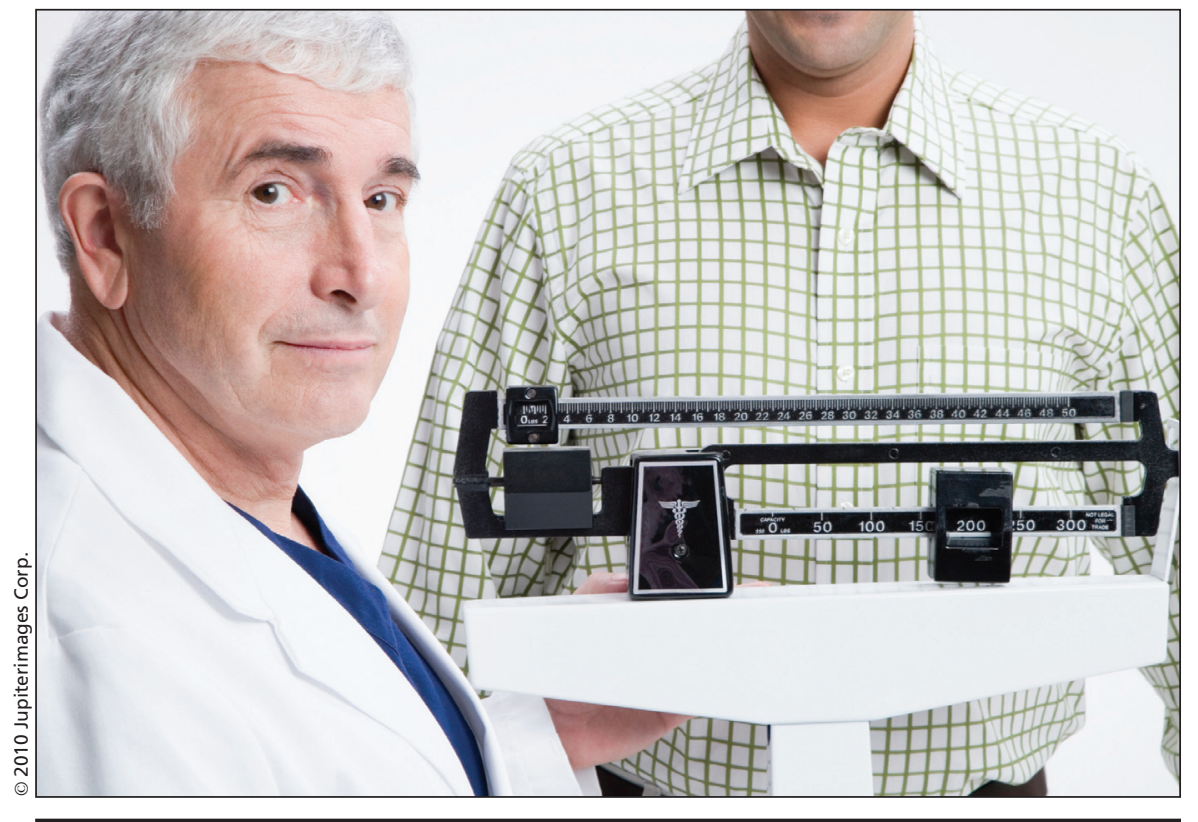

Family physicians will no longer be allowed to determine if a patient needs bariatric surgery. Rather, patients must be referred to regional assessment centres to make that determination.

ity to perform bariatric surgeries to 1470 from 244 per year. As many as 300000 Ontarians are believed to be in need of the procedure.

The new regime and new criteria will streamline the process and ensure that the right patients are selected for surgery, says Dr. Robert Dent, director of the Ottawa Hospital Weight Management Clinic, who provided input to the province on the changes and whose facility has been designated as a regional assessment centre. "People who just barely met the criteria were getting the surgery and people who really needed it weren't," he says.

The average family doctor is illqualified to make such a determination, Dent adds. "It's a highly specialized area. First you have to assess the patient to ensure they need it. Then you have to assess the patient to ensure they can tolerate it. Some people are not candidates for surgery. They're too high a risk. There has to be a lot of expertise to figure that out. There have to be specialized blood tests."

Dent says nearly 2000 Ontarians received surgery in the US in each of the past two years, at a minimum price of roughly US $\$ 19000$. That's $\$ 10000$ more than it costs to perform the surgery in Ontario, he adds. "Once the enterprising surgeons learned OHIP [Ontario Health Insurance Plan] was covering patients to go out-of-country, they would come up and give public lectures on it and recruit patients. And they would hand out the OHIP forms that required completion together with completing them or instructing people how to complete them."

"Then the patient would take the completed form, go to the family doctor, corner them; the family doctor would have to sign it because that was the missing link to get it approved by OHIP and many of those family doctors had no clue about bariatric surgery. This was a huge problem." 
Freedhoff counters that family doctors are fully qualified to decide whether a patient is a good surgical candidate. The ministry's criteria for bariatric surgery requires that a patient have a body mass index greater than 40 , or greater than 35 and at least one of: coronary heart disease, diabetes, obstructive sleep apnea or medical refractory hypertension despite optimal medical management. "This is not rocket science," he says.

But others praise the move.

"With bariatric surgery, you need the medical assessment and the psychological and emotional preparation. Very, very important," says Dr. Sean Wharton, director of the "no charge, OHIP-based" Wharton Medical Clinic in Hamilton, Ontario. "That is something that a patient going for gall bladder surgery doesn't need to have."

Gastric bypass surgery reduces the likelihood of patients dying from coronary artery disease, cancer and diabetes, Wharton says, citing a study that indicated that mortality rates were $56 \%$ lower for coronary artery disease, $60 \%$ for cancer and $92 \%$ for diabetes ( $N$ Engl J Med 2007; 357:2633-4)

"But they have increased risk of death from nonmetabolic conditions - which is accidents and suicides because so many of these patients were not appropriately selected or prepared to go to surgery," Wharton adds.

Freedhoff also argues that the regime will result in wait times of up to one year for bariatric surgery.

But Dent says wait times are increasing because of heightened awareness and demand for bariatric surgery. "The waiting time will go up no matter what you do. Because now more and more people are understanding this is a cure for type 2 diabetes, so the number of applicants has gone way, way up."

Dent also rejects the argument that sending patients to provincial referral centres will lengthen wait times. "The precedent is there. We have these for joint replacements; we have the knee clinic at the Ottawa Hospital so if the physician is worried about somebody's knees they send them here. They don't do the assessment and the actual referral for surgery. If a patient has leukemia, they don't do the treatment, they don't refer for a specific treatment. They refer to a centre that deals with it."

At least four other surgical "bariatric centres of excellence" or surgical sites will be established in Ontario, but Wharton says that isn't enough to meet demand. "There's none in the north. There's none between Toronto and Ottawa. ... How is somebody in North
Bay going to get to a program where they can see a dietitian and a nutritionist for a three-month duration and be able to get the proper education and psychological preparation that they need?"

"The waiting list is already a tremendously long list," he adds. "I think what this has done is made selection biased to the cities that have the regional assessment and treatment centres. So we will get done the 1000 to 2000 surgeries ... which will be similar to the amount we were sending for outof-country surgery which was 1600 , but they're all going to be from the province's major metropolitan areas."

Freedhoff believes the new regime is biased against obese people. "I can't think of any other surgery or access to consultation where there is this requirement that a person fail three months lifestyle intervention. You could argue blood pressure responds to lifestyle intervention. Perhaps depression or other mental illnesses might respond to lifestyle interventions. But we don't necessitate patients fail a program before they're allowed to access health care that we know can help them. It seems like a very, very, quite frankly biased double standard." - Becky Rynor, Ottawa, Ont.

DOI:10.1503/cmaj.109-3147 